Scientific Journal of October 6 University

ISSN (Print): 2314-8640

ISSN (Electronic): 2356-8119

Published by October 6 University @ All Rights Reserved

Available online at: http:// sjou.journals.ekb.eg

Original Article
Citation: Elgendy et al., (2014). Evaluation of Chitosan Membrane with or without Autologous Platelet Rich Plasma in the Treatment of Gingival Recession......: A Randomized Controlled Clinical Study. Sci.J. of Oct. 6 Univ. 2(2), 184-195.

Copyright: (C) 2014 Elgendy et al.. This is an open-access article distributed under the terms of the Creative Commons Attribution License, which permits unrestricted use, distribution, and reproduction in any medium, provided the original author and source are credited.

\title{
Evaluation of Chitosan Membrane with or without Autologous Platelet Rich Plasma in the Treatment of Gingival Recession: A Randomized Controlled Clinical Study
}

\author{
*Enas A. Elgendy ${ }^{1}$, Samia A. Darwish ${ }^{2}$, Samia N. Serag ${ }^{2}$ and Amal M. Aldeeb ${ }^{3}$ \\ ${ }^{1}$ Lecturer of Oral Medicine, Periodontology, Oral Diagnosis and Radiology Department, Faculty of \\ Dentistry, October 6 University \\ ${ }^{2}$ Prof. of Oral Medicine, Periodontology, Oral Diagnosis and Radiology Department, Faculty of Dentistry, \\ Tanta University \\ ${ }^{3}$ Prof. of Oral Pathology Department, Faculty of Dentistry, Tanta University
}

Received: 01-03-2014/ Revised: 01-04-2014 / Accepted: 10-04-2014

\begin{abstract}
Chitosan is known to be natural polymers and it is available, biodegradable, biocompatible, and non-toxic and has antimicrobial and anti-inflammatory effects. Platelet rich plasma (PRP) is an autologous source of platelet derived growth factor and transforming growth factor beta that play a role in periodontal regeneration. The present study was designed to evaluate and compare chitosan membrane with or without PRP versus CTG in the treatment of Miller Class I buccal gingival recession $\geq 4 \mathrm{~mm}$ in width. Thirty sites in patients with Miller Class I buccal gingival recession $\geq 4 \mathrm{~mm}$ in width were included in this study. The patients were classified randomly into three treatment groups, ten sites for each group. Selected recession sites were treated with one of the following three modalities. Group I: connective tissue graft in addition coronally advanced flap. Group II: chitosan membrane in addition coronally advanced flap. Group III: chitosan membrane, autologous platelet-rich plasma in addition coronally advanced flap. Plaque index (PI), gingival index (GI), probing pocket depth (PPD), clinical attachment level (CAL), recession height (RH), recession width (RW), digital measurements of area of recession and height of the keratinized tissue (HKT) were recorded at baseline and at 1, 3,6 and 12 months post surgically, except for PPD \& CAL which were assessed at 6 and 12 months post surgically. Gingival thickness (GT) was recorded at baseline and after 12 months post surgically. Percentage of root coverage (RC) was recorded at 1, 3, 6, 12 months and wound healing index (WHI) was recorded at 2 weeks, 1, 3, and 6 months after surgery. All groups showed comparable results at the end of the study period. The three treatment modalities showed a statistically significant reduction in CAL at 6 and 12 months as compared to the mean baseline value. Intergroup comparison showed that group III had significantly less RH, RW, and digital measurement of recession area as compared to group I at one month, while there was statistically insignificant difference between group II and I. On the other hand, the results at 3,6 and 12 months post-surgery were comparable and statistically insignificant. Difference in all treated groups there was a statistically significant increase in the mean HKT up to 12 months as compared to the mean baseline value. However, CTG lead to more HKT as compared to groups II \& III. There was a statistically significant increase in the mean GT after 12 months post-surgery in all treated groups. The mean GT was more significantly increased in group I \& III as compared to group II. A statistically significant reduction in WHI in chitosan membrane and chitosan membrane and PRP groups when compared to the CTG group at 2 weeks post-operatively. Clinical results of the present study indicated that, the addition of chitosan membrane with or without PRP to CAF resulted in root coverage comparable to CTG but without the discomfort as in the second surgical procedure and the potential clinical difficulties associated with the donor site surgery. Clinically the addition of PRP to chitosan resulted in an increase gingival thickness as compared to chitosan membrane alone. Gingival thickness in group III (chitosan with PRP) was comparable to CTG.
\end{abstract}

Key Words: Gingival recession, Connective tissue graft, Chitosan, Platelet rich plasma

\section{Introduction}

Gingival recession is defined as the displacement of the marginal tissue apical to the cement enamel junction. Histologically, the destruction of gingival tissues, due to mechanical forces or inflammatory periodontal disease, is associated with loss of periodontal connective tissue fibers and alveolar bone. As a consequence, 
exposure of the root surface to oral environment will occur ${ }^{(1)}$.

Gingival recession and root exposure have presented a therapeutic challenge to clinicians for many years. Patients often complain about poor esthetics and root sensitivity. Later on, the longlasting recessions will be complicated by root caries and erosion. With an increased awareness of esthetics by both patients and dentists, various surgical procedures have been designed to correct gingival deformities esthetically as well as functionally. The main indications for root coverage procedures include esthetic demands, root sensitivity, and shallow carious lesions ${ }^{(2)}$.

Many techniques have been introduced to treat gingival recession, including autogenous free connective tissue grafts (CTG), coronally positioned flaps, orthodontics, pedicle grafts, free gingival grafts and guided tissue regeneration $(\mathrm{GTR})^{(3)}$. Coronally advanced flap $(\mathrm{CAF})$ is one of the most effective treatments of Miller Class I and II recession defects. The mean percentage of root coverage obtained with this technique ranges from $55 \%$ to $99 \%$ (4-7). CAF may lead to excellent esthetics results, avoiding the need for a second surgical site; moreover, it is simple to perform and can be used to treat multiple recessions ${ }^{(8)}$.

CAF is sometimes problematic on account of the fragility of the gingival tissues and/or lack of attached gingiva. The subepithelial connective tissue graft (CTG), traditionally harvested from the patient's palate, is commonly used for root coverage in periodontal recession defects ${ }^{(9)}$. The CTG obtains a closer color blend and keloid appearance is avoided compared to free gingival graft $(\mathrm{FGG})^{(10)}$. The different studies in the literature have confirmed the good results of this technique and subsequently it is considered as a gold standard therapy for patients with gingival recession ${ }^{(10-12)}$. A limiting factor of this technique is the requirement of a remote surgical site to harvest the connective tissue. Often the donor site has more morbidity than the graft site and is associated with surgical challenges for the clinician. In addition, the amount of donor tissue is limited for any single surgical procedure ${ }^{(9)}$.

Guided tissue regeneration has become part of everyday surgical periodontal practice. These treatment modalities use barrier membranes which exclude fast growing cells (i.e., gingival epithelial, gingival fibroblasts) while enabling mesenchymal progenitor proliferation and differentiation into osteoblasts, periodontal ligament fibroblasts, and cementoblasts $^{(13)}$. These progenitor cells, given the space and enough time, are capable of restoring lost attachment around teeth $^{(14)}$.

Non-absorbable membranes have become less popular due to the need for a second surgery to retrieve them, and bioabsorbable membranes with comparable, if not better, clinical outcomes have become first choice in regenerative therapy.
Commercially available bioabsorbable membranes are prepared from: dura-mater ${ }^{(15)}$, polylacticacid ,polyurethane ${ }^{(16)}$, polyglycolic acid ${ }^{(17)}$, and collagen (14)

Platelet-rich plasma (PRP) is an autologous source of platelet-derived growth factor and transforming growth factor that is obtained by sequestering and concentrating platelets by gradient density centrifugation $^{(18)}$. Platelet-derived growth factor (PDGF) is a family of polypeptide growth factors consisting of 2-chain polypeptides linked by disulfide bonds. PDGF is stored in the alpha granules of platelets and released during the clotting cascade PDGF acts as a potent mitogen in serum for mesenchymal cells, including fibroblasts and smooth muscle cells. and transforming growth factor (TGF) is a 2-chain polypeptide that is linked together by disulfide bonds TGF stimulates angiogenesis and the production of fibronectin, glycosaminoglycans, and collagen in connective tissue. One of the most important functions of TGF seems to be the chemotaxis and mitogenesis of osteoblast precursors. In addition, this polypeptide inhibits osteoclast formation \&resorption and favoring bone formation ${ }^{(19)}$.

Natural products have served as a major source of drugs for centuries, and about half of the pharmaceuticals in use today are derived from natural products ${ }^{(20)}$. Oriental medicines have been evaluated for their effects on periodontal disease, antibacterial and anti-inflammatory effects and periodontal tissue regeneration ${ }^{(21)}$. Among these materials, chitosan (poly-N-acetyl glucosamineoglycan), is a derivative of chitin, which is the second most abundant natural biopolymer, and which is a primary structural component of the exoskeleton of arthropods such as crustaceans, the cell wall of fungi, and the cuticle of insects. Chitosan is obtained by M-acetylating chitin, and it is a biodegradable natural biopolymer that is nontoxic and non-immunogenic ${ }^{(22)}$.

The inductive and stimulatory activity of chitosan on connective tissue rebuilding was clearly demonstrated, and it was suggested that it could be considered a primer on which normal tissue architecture is organized ${ }^{(23)}$. In addition, studies have shown that chitosan has both antibacterial ${ }^{(24)}$, and anticandidal effects ${ }^{(25,26)}$.

Due to the previously mentioned potentially beneficial properties of both chitosan and chitosan with PRP, the aim of this study was to compare the efficacy of these treatment modalities in sites with gingival recession.

Patients selection:

\section{Material and Methods}

This study included 30 sites in patients with Miller Class I buccal gingival recessions $(\geq 4 \mathrm{~mm}$ width as measured from the cemento-enamel junction) in maxillary and mandibular incisors and canines, from the Periodontology Clinic, Faculty of 
Dentistry, Tanta University. The patients' ages ranged between 20 to 45 years, their consent was required and all procedures were explained before treatment.

Inclusion criteria:

- Patients with good systemic health and no contraindication for periodontal surgery.

- Patients who are able to maintain good oral hygiene.

- Gingival thickness for the site selected should be $\geq 1 \mathrm{~mm}$.

- The height of keratinized gingiva (HKG) for the site selected should be $\geq 1 \mathrm{~mm}$ (HKG is the distance between the most apical point of the gingival margin and the mucogingival junction).

Exclusion criteria:

- Active infectious diseases (hepatitis, tuberculosis, HIV, etc....).

- Medically compromised patients.

- Patients taking medications known to cause gingival enlargement.

- Pregnant patients and smokers or abuse.

- Previous mucogingival surgery at the defect.

- Restorations or caries in the area to be treated and non vital tooth.

- Teeth which are tilted or rotated.

- Participation in other clinical trials.

\section{Materials:}

1- Chitosan (poly-N-acetyl glucosaminoglycan) powder was purchased from Sigma® ${ }^{\circledR}$ (P.O. Box 14508. ST. LOUIS, MO 63103 USA), and chitosan membrane was prepared.

2- Autologous platelet-rich plasma was prepared according to Marx et al ., ${ }^{(18)}$.

3- Tetracycline hydrochloride solution $(10 \mathrm{mg} / \mathrm{ml})$ was prepared by adding $250 \mathrm{mg}$ tetracycline powder from capsules to $25 \mathrm{ml}$ distilled water at room temperature.

The clinical study design:

Phase I therapy:

- All patients received proper oral hygiene instructions. The patients were instructed to perform a non-traumatic brushing technique using a soft toothbrush to avoid habits related to the etiology of recession. All of patients were subjected to full mouth scaling, root planing (SRP). In addition, occlusal adjustment was performed if signs of trauma were evident. Alginate impressions of both the upper and the lower jaw were taken and study casts were fabricated.One month following phase one therapy, all patients were evaluated to ensure the local fitness for surgical procedure.

Patient groups:

After phase I therapy, the patients were classified randomly by the sealed envelopes technique into three treatment groups, ten patients for each group. Selected recession sites were treated with one of the following three modalities:
Group I: Connective tissue graft + coronally advanced flap

Group II: Chitosan membrane + coronally advanced flap.

Group III: Chitosan membrane + autologous platelet-rich plasma + coronally advanced flap.

\section{Clinical assessment:}

1.Plaque Index $(\mathrm{PI})^{(27)}$

2. Gingival index $(\mathrm{GI})^{(28)}$

3. Probing pocket depth (PPD) and Clinical attachment level (CAL) ${ }^{(29)}$

4. Recession height (RH): distance between cemento-enamel junction (CEJ) to the most apical point of the gingival margin (GM).

5. Recession width (RW): from one border of the recession to another, measured at the CEJ.

6. Height of the keratinized tissue (HKT): distance between the most apical point of the GM and the mucogingival junction (MGJ).

All these clinical parameters were recorded at baseline and at 1, 3, 6 and 12 month post surgically, except for PPD \& CAL which were assessed at 6 and 12 months post surgically.

7. Gingival thickness (GT)was measured at the mid-buccal $2 \mathrm{~mm}$ apical to the free gingival margin (at baseline and after 12 months post-surgery) by penetrating a probe into the tissue ${ }^{(30)}$.

8. Percentage of root coverage ( $\mathrm{RC})$ : was calculated after 1, 3, 6, 12 months as [RH preoperative - RH postoperative]/RH preoperative) x $100 \%$.

9. Digital measurements: all recession areas were photographed before surgery and at 1, 3, 6 and 12 months after surgery. The photos included a periodontal probe positioned on the site of recession. To ensure reproducible measurements, these photos were transferred to the computer from a digital camera which was adjusted at fixed resolution for all photos. The area of recession were examined and measured on autocad software (Autocad, Autodesk company 111 Mclnnis Parkway San Rafael, California 94903, USA).

10. Wound healing index (WHI): was recorded at 14 days and 1,3 , and 6 months after surgery using Huang et al., criteria $^{(30)}$.

\section{The surgical phase:}

I) Surgical protocol for CAF and CTG according to Langer \& Langer, ${ }^{(31)}$.

II) Surgical protocol for $\mathrm{CAF}$ and chitosan membrane:

A local anesthetic was injected to the area selected for surgery. Root planing of the exposed root surfaces was carried out until the root surfaces were hard and smooth. Two horizontal incisions were made at right angles to the adjacent interdental papillae at the CEJ level without interfering with the gingival margin of the neighbouring teeth. To mobilize the flap, two oblique vertical releasing incisions were extended beyond the mucogingival junction. A full thickness trapezoidal flap was then elevated up to the mucogingival junction, and 
following penetration of the periosteum, a partial thickness flap was dissected further apically. The papillae mesial and distal to the recession defects were deepithelialized. Following conditioning, the root surface (as described previously) the chitosan membrane was trimmed and positioned to cover the recession up to CEJ. The flap was then coronally advanced to cover the membrane and flap was closed using simple interrupted sutures (figure 1). A periodontal dressing was placed over the recipient site for 10 days to protect the wounds.

III) Surgical protocol for CAF, chitosan membrane and autologous platelet-rich plasma (PRP): The same surgical protocol for CAF and chitosan membrane except that the membranes were embedded in the prepared PRP before covering the recession sites.

All of the surgical procedures were performed by the same surgical team.

Pre- surgical and post-surgical clinical assessments were carried out by a periodontist who was unaware of the surgical technique used for each group. In addition, the data were sent to the statistician without specification of the surgical technique for each treatment group to avoid bias.

\section{Post operative care:}

- Doxycycline $100 \mathrm{mg}$ was prescribed twice daily the first day, then $100 \mathrm{mg}$ once daily for 10 days.

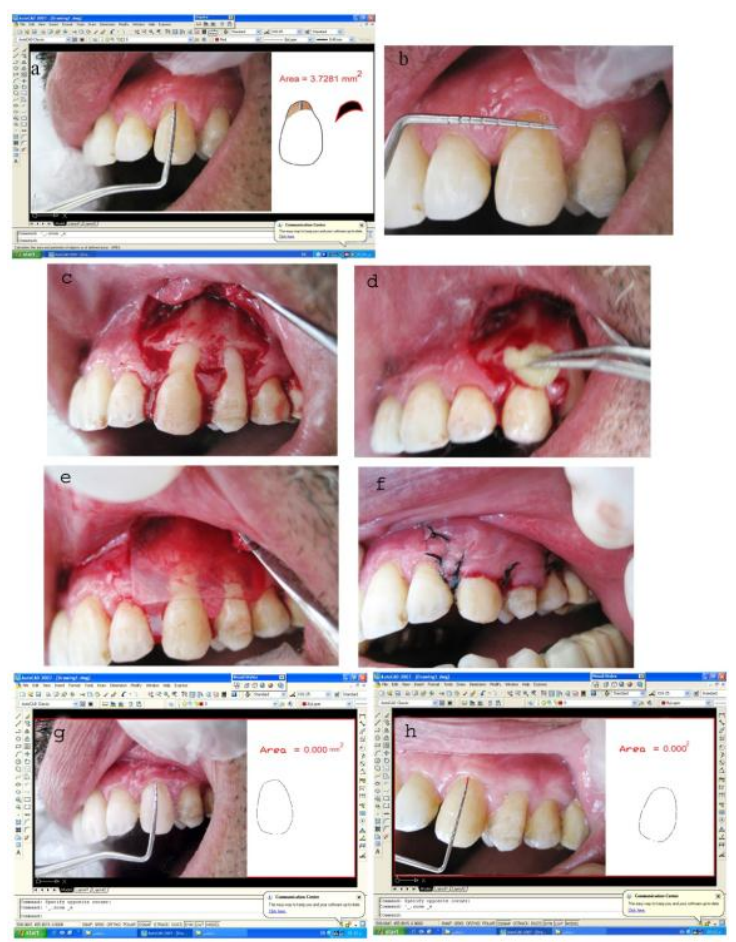

Figure (1): a,b Measurement of the recession hight, width and digital measurement of recession area, c,d, a full thickness flap extended to MGI and conditioning of the exposed root surface with tetracycline $\mathrm{HCl}$, e,f, chitosan membrane adapted to cover area of recession and the flap coronally advanced to completely cover the chitosan membrane and sutured, g,h, mesurment of the recession area at 1, 12 months post surgery showing complete root coverage.

- Analgesics (non-steroidal anti-inflammatory drugs) were prescribed to control postoperative discomfort (Brufen $600 \mathrm{mg}$, one tablet every 8 hours for 48 hours).

- A soft diet, a mouth rinse with $0.12 \%$ chlorhexidine solution was recommended twice daily for 10 days.

- The patients were instructed not to brush or floss the operated area and avoid hard and spicy food for 2 months.

- After pack removal (10 days post operatively) the patients were instructed to clean the surgical sites with a cotton pellet soaked in a $0.12 \%$ chlorhexidine solution four times daily for 2 months. Two months after surgery, all patients were instructed for plaque control using a soft toothbrush and a coronally directed roll-technique to minimize the toothbrushing trauma to the gingival margin.

- All patients were recalled for professional prophylaxis and plaque control and tongue brushing once a week during the first month, bimonthly until the third month, and once a month until the final assessment 12 months post-operative.

\section{Results}

After 2 weeks post-surgically until 6 months, a questionnaire was given to each patient at the evaluated periods. The questionnaire recorded the results of the procedures relative to esthetics, root sensitivity (before and after surgery), and comfort during the postoperative period. Regarding the postoperative period, no patients in group II and III experienced pain, while patients in group I had postoperative pain and greater discomfort which was attributed to a painful palate wound in the donor area. Accordingly a greater consumption of analgesics was required. All groups experienced an esthetic improvement and patients were generally satisfied. In addition there was a reduction in root hypersensitivity in all treated groups. The surgical procedures of the three treatment modalities were well tolerated by the patients without any complications. The improvement in the clinical parameters was markedly observed in all treatment modalities, which was maintained up to 12 months. At baseline, the three treatment groups showed no statistical significant differences regarding the tested clinical parameters $(\mathrm{P}>0.05)$ (Tables $1 \& 2)$.

Results of group I, II \&III, showed a significant reduction in the mean PI \& GI which continued up to the end of 12 months as compared to the mean baseline value. In group I, the mean PI \& GI, decreased from $1.07 \pm 0.62,1.30 \pm 0.35$ at baseline to $0.72 \pm 0.25, \quad 1.05 \pm 0.37$ respectively, but this decrease was statistically insignificant. At all evaluation periods ANOVA test showed statistically insignificant difference between the three treated groups. 
Results of group I, II \&III revealed that there was reduction of PPD at 6 and 12 months post surgery, but this reduction was statistically insignificant as compared to the mean baseline value (table 1). At all evaluation periods ANOVA test showed insignificant difference in PPD between the three treated groups at any time of evaluation periods.

Table (1) demonstrates a statistically significant reduction in the mean CAL up to 12 months as compared to the mean baseline value in group I, II \&III $(\mathrm{P}<0.05)$. At all evaluation periods ANOVA test showed an insignificant difference between the three treated groups at any time of the evaluation period.

Results of patient's sites in group I, II \&III revealed that the mean RH \& RW were reduced. This reduction was statistically significant as compared to baseline values at any time of the evaluation period $(\mathrm{P}<0.05)$. At 1 month post surgery there was a statistically significant reduction in the mean of RH\&RW in the group III (chitosan membrane + $\mathrm{PRP}+\mathrm{CAF})$ as compared to group I $(\mathrm{CTG}+\mathrm{CAF})$ $(\mathrm{P}<0.01)$. While there was statistically insignificant difference between group I (CTG + CAF) and group II (chitosan membrane $+\mathrm{CAF}$ ) or between group II (chitosan membrane $+\mathrm{CAF}$ ) and group III (chitosan membrane + PRP + CAF) at 1 month. ANOVA test showed statistically insign-ificant difference between the three treated groups at 3,6, and 12 months of evaluation periods.

Patients sites treated with CTG + CAF showed an increase of the mean HKT from $4.00 \pm 2.00$ to $5.40 \pm 1.78$ and $6.40 \pm 1.78$ at 1 and 3 months respectively. This increase was statistically insignificant as compared to baseline value. At 6 and 12 months mean of HKT was $6.70 \pm 1.64$ and $6.70 \pm 1.64$ respectively. This increase was statistically significant as compared to baseline values $(\mathrm{P}<0.05)$.

Results of patients treated with chitosan membrane + CAF revealed that the mean HKT had increased from $4.90 \pm 0.99$ at base-line to $6.00 \pm 1.05$, at 1 month and this increase was maintained until the end of evaluated period. At 1 month this increase in HKT was statistically insignificant as compared to baseline value. However, at 3, 6 and 12 this increase was statistically significant as compared to baseline value $(\mathrm{P}<0.05)$.

At one month post-operatively sites treated with chitosan membrane + CAF + PRP showed increases of HKT from $5.20 \pm 1.75$ at base-line to $6.90 \pm 1.85$ at one month post-operatively and this height was maintained until 3 and 6 months. This increase was statistically insignificant compared to the baseline value. At 12 months the mean HKT was $7.00 \pm 0.95$ and this increase was statistically significant as compared to baseline values $(\mathrm{P}<$ 0.05). ANOVA test showed statistically insignificant difference between the three treated groups at $1,3,6$, and 12 months of evaluation periods. Results of group I, II \& III revealed that there was no statistically significant in $\mathrm{RC}$ at 3,6 and 12 months evaluation periods compared to the mean RC at 1 month. At 1 month post surgery the mean difference was a statistically significant increase in RC in the group III (chitosan membrane $+\mathrm{PRP}+\mathrm{CAF})$ as compared to group I (CTG + $\mathrm{CAF})(\mathrm{P}<0.05)$. However, there was statistically insignificant difference between group I (CTG + $\mathrm{CAF}$ ) and group II (chitosan membrane $+\mathrm{CAF}$ ) or between group II (chitosan membrane $+\mathrm{CAF}$ ) and group III (chitosan membrane + PRP+ CAF). ANOVA test showed statistically insignificant difference between the three treated groups at 3,6, and 12 months of evaluation period $(\mathrm{P}>0.001)$.

In group I, Table (2) demonstrates a statistically significant reduction in the mean WHI up to 12 months as compared to the mean WHI at 14 days (1.55 \pm 0.53$)$. After 1 month the mean WHI was $1.00 \pm 0.00$ and this reduction maintained until the 6 months evaluated period. This reduction was statistically significant as compared to 14 days post surgery $(\mathrm{P}<0.05)$.

Results of patients sites treated with chitosan membrane + CAF and chitosan membrane + CAF + PRP revealed that the mean WHI was stable at 14 days, 1,3 and 6 months of evaluation period (1.00 \pm 0.00$)$. At 14 days post surgery, there was a statistically significant reduction of the mean of WHI in group II (chitosan membrane + CAF) and group III (chitosan membrane $+\mathrm{PRP}+\mathrm{CAF}$ ) as compared to group I $(\mathrm{CTG}+\mathrm{CAF})(\mathrm{P}<0.01)$. At 1 , 3 and 6 months of evaluation period ANOVA test showed no statistically significant difference between the three treated groups $(\mathrm{P}>0.05)$.

Results of group I, II \& III, showed a statistically significant increase of mean GT from $1.00 \pm 0.00$ at baseline to $1.35 \pm 0.24,1.20 \pm 0.26$ and $1.35 \pm 0.34$ at 12 months post-surgery $(\mathrm{P}<0.05)$. At base-line and 12 months of the evaluation period ANOVA test showed statistically insignificant difference between the three treated groups $(\mathrm{P}>0.05)$.

Table (2) demonstrates a statistically significant reduction in the mean digital measurement area of recession at 1, 3, 6 and 12 months in all treated group as compared to baseline values $(\mathrm{P}<0.05)$. At 1 month post surgery there was a statistically significant reduction in the mean of digital measurement area of recession in the group III (chitosan membrane $+\mathrm{PRP}+\mathrm{CAF}$ ) as compared to group I $(\mathrm{CTG}+\mathrm{CAF})(\mathrm{P}<0.01)$. While there was statistically insignificant difference between group I (CTG + CAF) and group II (chitosan membrane + $\mathrm{CAF}$ ) or between group II (chitosan membrane + $\mathrm{CAF}$ ) and group III (chitosan membrane + PRP+ CAF) at 1 month. ANOVA test showed statistically insignificant difference between the three treated groups at 3, 6, and 12 months of evaluation periods. 


\section{Discussion \\ Evaluation of clinical results: \\ Plaque index (PI), gingival index (GI) and wound healing index (WHI):}

In this study, all the tested groups had comparable oral hygiene condition as evidenced by their mean PI score at baseline. Results of the present study showed that there was a reduction in the mean PI and GI scores during the study periods in all groups as compared to baseline values. After 1 month, there was a reduction in PI and GI, inspite of no tooth brushing, and this could be attributed to the antiplaque mode of action of chlorhexidine (CHX). It is postulated that $\mathrm{CHX}$ achieved its antiplaque effect as a result of an immediate bactericidal action at the time of application, followed by a prolonged bacteriostatic action as a result of $\mathrm{CHX}$ adsorbing to the pellicle coated enamel surface. This implied that tooth surface bound CHX is of great importance in preventing plaque formation ${ }^{(32)}$. In the current study, group II and group III showed a more significant reduction in PI and GI after one month post-surgery as compared to group I in spite of no tooth brushing. At 2 weeks there was a notable statistically significant difference between the three groups in the healing pattern observed as recorded by WHI. At 2 weeks, the healing in group II and in group III was more satisfactory as compared to that observed in group I. However, the mild postoperative complication in group I (redness or swelling, patient discomfort) did not jeopardize the final clinical outcome. Nonetheless, the WHI reached a plateau one month after surgery in all treated groups. The reduction in PI \& GI and WHI in the presence of chitosan and PRP could be attributed to the antimicrobial effect of chitosan. The antimicrobial action of chitosan has been postulated to occur by several mechanisms. Chelation is an important factor, deprivation of metals, trace elements or essential nutrients by chelation, limits the growth of microorganisms ${ }^{(25)}$. The highly reactive amino groups in chitosan have the ability to interact with anionic groups on the cell surface and to form polyelectrolyte complexes with bacterial surface compounds, there by forming an impermeable layer around the cell, which prevents the transport of essential solutes into the cell and produce disturbances of membrane functions ${ }^{(24,33)}$. In addition, the effect of chitosan on the reduction of GI could be attributed to the anti-inflammatory effect of both chitosan and PRP for the previously mentioned reasons ${ }^{(34,35)}$.

The diminished post-surgical inflammation in group III could be attributed to that PRP delivers considerable amounts of regulated on activation normal T-cell expressed and secreted (RANTES) to the wound. RANTES, a chemokine that is regulated upon activation, expressed normally in $\mathrm{T}$ cells, and known as chemokine (C-C motif) ligand 5 (CCL5), could have a dual role in inflammation. As a mediator of the inflammatory process,
RANTES increases the adherence of monocytes to endothelial cells ${ }^{(36)}$, which, in turn, could be a potent chemo-attractant to and activator of monocytes ${ }^{(37)}$. RANTES also can inhibit the release of histamine from basophils induced by several cytokines, leading to an inhibition of inflammatory processes and a shift in the wound environment toward repair and healing. Platelet-mediated RANTES originates from the alpha granules in platelets and could have beneficial effects in controlling the inflammatory processes ${ }^{(38)}$. Also PRP contains a high concentration of leukocytes that could act as an autologus antibiotic reducing the risk of infection ${ }^{(39)}$.

An interesting mechanism which may have contributed to the reduction of post-surgical inflammation is that PRP lead to a significant inhibition in monocyte chemotactic protein -1 (MCP-1) release by monocytes. MCP-1 is a member of the $\mathrm{CC}$ chemokine family and is produced by various cells, including monocyte/ macrophages in response to proinflammatory stimuli. In monocytes, MCP-1 induced chemotaxis and the respiratory burst, rapid induction of arachidonic acid release, and changes in $\mathrm{Ca}^{2+}$ concentration. Thus, these findings suggested that in addition to the increased growth factor release, PRP suppresses MCP-1 release by monocytes and reduce monocyte-mediated inflammation and enhance wound healing ${ }^{(40)}$.

Probing pocket depth (PPD) and clinical attachment level (CAL) results evaluation:

Results of PPD revealed that there was a reduction at 6 and 12 months evaluation period but this reduction was statistically insignificant as compared to the mean baseline value. A statistically significant reduction in the mean CAL up to 12 months as compared to the mean baseline value was observed in all groups. The difference between the three groups was insignificant at any time of the evaluation period.

The improvement of CAL and PPD was demonstrated by Muzzarelli et al., ${ }^{(41)}$ and Akncbay et al., ${ }^{(42)}$ who examined the ability of chitosan gel to improve PPD and CAL in chronic periodontitis. The authors concluded that chitosan is bioadhesive and the reduction in PPD and CAL values could be allowed by chitosan because of its supportive and organizing effect on histological architecture of the gingiva. Furthermore, Zhang et al., ${ }^{(4)}$ found that chitosan inhibited the degra-dation of extracellular matrix, stimulated the expression of type I collagen and up-regulated alkaline phosphatase.

The role of PRP in periodontal regeneration was reported by deObarrio et al., ${ }^{(39)}$, Camargo et al., ${ }^{(44)}$, Lekovic et al., ${ }^{(4)}$ and Okuda et al., ${ }^{(46)}$. They demonstrated a significant reduction in probing depth \& clinical attachment gain and formation of significant amount of new bone as compared to baseline values in humans. A mechanism by which 
PRP improved the amount of bone was by virtue of PDGF and TGF- $\beta$. PDGF is chemotactic for periodontal ligament osteoblasts and fibroblasts and promotes primary nonc-ollagenous protein synthesis in bone culture ${ }^{(39)}$. Also, TGF- $\beta$, a constituent of PRP, has a very potent effect on cells associated with bone. It has been shown to promote bone formation and improve healing in calvarial defects of adult male rats when compared to controls $^{(47)}$

Results of the present study differ from the clinical study by Huang et al., ${ }^{(30)}$ who carried out his study to evaluate the effect of application of PRP with CAF. The authors concluded that, the application of PRP in CAF for root coverage provided no clinically measurable enhancements on the final therapeutic outcomes of CAF in Miller's class I recession defects. In the current study PRP was added to chitosan which may have acted as a scaffold for PRP and hence more effective results were found.

Evaluation of recession height $(\mathrm{RH})$, recession width (RW), percentage of root coverage (RC) and digital measurement of recession area results:

At one month, group III had significantly less $\mathrm{RH}, \mathrm{RW}, \mathrm{RC}$ and digital measurement of recession area as compared to group I, which in turn was comparable to group II. However, the reduction increased over time in group I, by the sixth month and was sustained up till 12 months. In all treated groups there was a statistically significant reduction in the mean RH, RW \& digital measurement of recession area and increase in percentage of $\mathrm{RC}$ up to 12 months as compared to the mean baseline value. There was no statistical significant difference in recession depth between the three groups at 3,6 and 12 months.

The progressive improvement in root coverage in group I which was observed in the current study may be explained by Papageorgakopoulos et al., ${ }^{(4)}$ who contends that the continuous improvement in root coverage might be attributed to the creeping which occur with CTG and not present with CAF. Goldman \& Schluger ${ }^{(4)}$ were the first to describe "creeping attachment" as the increased gingival coverage over a denuded root surface that takes place over an extended period of time after surgery. Borghetti \& Gardella, ${ }^{(50)}$ contends that any increase in attachment after 1 month of healing should be considered creeping attachment. In a related effort evaluating the long-term success of CTG Harris, ${ }^{(51)}$ found that root coverage increased, on an average, of $0.4 \mathrm{~mm}$ with time. Lee et al., ${ }^{(52)}$ found that at 3 years, $72.7 \%$ of sites treated by CTG with a CAF exhibited creeping attachment, with an average increase of $0.55 \mathrm{~mm}$ of coverage and reported creeping attachment was highest at 12 months. Creeping is an important concept not only it is important in regard to the time frame of a study of root coverage, but also, it can be clinically valuable when total root coverage requires only minimal additional attachment. In group II and III, the tangible improvement in this parameter was from the first month and no further improvement in these parameters was observed. Results of the present study indicated that no significant difference was noted in percentage of root coverage in all groups at the end of the study period.

\section{Evaluation of height of the keratinized tissue (HKT) and gingival thickness results:}

In all treated groups there was a statistically significant increase in the mean HKT up to 12 months as compared to the mean baseline value. There was no statistical significant difference in HKT between the three groups at 1, 3, 6 and 12 months.

One of the well recognized benefits of the CTG is the amount of keratinized tissue consistently produced. Height of the keratinized tissue increased significantly in all treated groups in the present study. CTG produced significantly greater increases in HKT as compared to baseline values, perhaps because dense connective tissue harvested from the palate has the potential to induce keratinization of the epithelial cells of the covering flap. In GTR procedures, an increase in HKT is derived from the proliferation of granulation tissue from the periodontal ligament ${ }^{(53)}$. There is some evidence in the literature that the mucogingival line is a stable landmark throughout life ${ }^{(54)}$. The increase of keratinized tissue changes obtained after CAF seems to validate the importance of the mucogingival junction tendency to regain its genetically defined position rather than attributing a significant role to the granulation tissue deriving from the periodontal ligament tissue and migration below the membrane to increase the dimension of the gingiva ${ }^{(55)}$.

Wennström \& Zucchelli ${ }^{(56)}$ reported no statistically significant differences between coronally advanced flaps alone and in combination with a subepithelial connective tissue graft, with the exception of the increase in gingival height where the combination therapy resulted in over twice the gingival height, $2.8 \mathrm{~mm}$ as opposed to $1.1 \mathrm{~mm}$. Wang et al., ${ }^{(57)}$ reported $0.7 \mathrm{~mm}$ gain in keratinized tissue with coronally advanced flap over a collagen membrane as compared to $1.1 \mathrm{~mm}$ gain in keratinized tissue with the subepithelial connective tissue graft. McGuire \& Nunn, ${ }^{(58)}$ demonstrated the average gain of $4.06 \mathrm{~mm}$ of keratinized tissue at 12 months for the subepithelial connective tissue graft (control) versus $3.11 \mathrm{~mm}$ for the coronally advanced flap with EMD (test). In the present study the amount of keratinized tissue in CTG increased over time with a significant difference in the amount of keratinized tissue evident at 6 and 12 months when compared to the baseline. 
Hwang \& Wang, ${ }^{(59)}$ concluded that gingival thickness has a bearing on the mean and complete root coverage gained from different treatment modalities, in particular CTG and GTR. Allen \& Miller ${ }^{(4)}$ indicated that thick gingival tissue $(\geq 1$ $\mathrm{mm}$ ) was needed for successful root coverage with a CAF. Accordingly the present study, an initial gingival thickness of $\geq 1 \mathrm{~mm}$ was selected. Thick gingiva in the recipient site seems to be advantageous as, in theory, it harbors more patent vessels and eases surgical manipulation and this can be another cause for the greater RC in this study in all groups.

In the present study, there was statistically significant increase in the mean GT after 12 months post-surgery in all treated groups. The increase in mean GT was statistically more significant in groups I \& III as compared to group II. One of the most important factors increasing the risk for gingival recession is thin and delicate marginal tissue. Therefore, favorable results obtained following surgical procedures for root coverage should not only result in an increased width of the keratinized tissue but also gingival thickness which decrease the likelihood for recession recurrence ${ }^{(60)}$.In the present study, there was statistically significant increase in the mean GT after 12 months post-surgery in all treated groups. The increased thickness in group II and III may be attributed to the effect of chitosan on proliferation of human fibroblasts. It has been postulated that chitosan may function in a similar way to hyaluronan ${ }^{(61)}$. Chitosan may accelerate fibroblast proliferation indirectly, possibly through forming polyelectrolyte complexes with serum components such as heparin or potentiating growth factors such as platelet derived growth factor (PDGF) which is present in PRP in group III. They also suggested that chitosan act as a progression factor in mitogenesis induced by PDGF. PDGF is regarded as a competence factor that requires the presence of progression factors, such as insulin, to induce cell proliferation ${ }^{(62)}$. The more favorable results in GT increase in group III may have been due to the fact that cell proliferation induced by PDGF was stimulated by both insulin and chitosan, thus chitosan may mimic insulin or heparin, acting as a progression factor ${ }^{(63)}$.

In addition, PRP has many growth factors which are strong mitogenic and anabolic properties. These growth factors stimulate the proliferation of fibroblasts and periodontal ligament cells, as well as extracellular matrix formation, and promote collagen and total protein synthesis (64), while stimulating the synthesis of hyaluronate from gingival fibroblasts ${ }^{(65)}$.

\section{Conclusions}

Based on the results of the present study, it could be concluded that:

- Both chitosan membrane and PRP were clinically safe with no adverse reactions and were well tolerated by the tissues.

- Chitosan and PRP seemed to have antiinflammatory and antibacterial effects as evidenced by PI, GI and early improvement of WHI as compared to CTG.

- The low cost chitosan membrane may be used as an alternative to CTG in the treatment of Miller Class I buccal gingival recession since it would avoid a second surgical site for graft retrieval and offers tangible patient benefits in terms of less post operative pain in addition to the fact that it is easier to carry out by the operator.

\section{Recommendation}

- Chitosan membrane or chitosan membrane + PRP could be used as an alternative to CTG in the treatment of Miller Class I buccal gingival recession. Further studies are needed to assess the effect of these treatment modalities on Miller Class II \& III.

- Results of the present investigation create a new avenue for further studies on the effect of the chitosan membrane or chitosan membrane + PRP in the treatment of furcation defects and other intrabony defects or as guided bone regeneration in dental implants and ridge augmentation.

- Further studies to assess whether chitosan could be used as an adjunct to conventional periodontal therapy in the form of locally delivered gel, or incorporated in a biodegradable chip, comparable to chlorhexidine chip (Perio chip), for the treatment of refractory periodontally diseased sites.

- Since PRP + chitosan resulted in greater gingival thickness, further studies are needed to assess whether this combination could give favorable results in gingival recession areas with initially thin gingival margin.

- The possible release of growth factors from PRP by chitosan should be studied and compared to thrombin.

Conflict of Interest statement: The author declares no conflicts of interest. 
Table (1): Mean values of plaque index (PI), gingival index (GI), probing pocket depth (PPD in mm), clinical attachment level (CAL in $\mathrm{mm})$, recession height (RH in $\mathbf{m m}$ ) among the study groups at evaluation periods.

\begin{tabular}{|c|c|c|c|c|}
\hline Variable & Group & $\begin{array}{l}\text { Group I } \\
(\mathbf{n}=\mathbf{1 0}) \\
\text { Mean } \pm \text { SD }\end{array}$ & $\begin{array}{l}\text { Group II } \\
(\mathbf{n}=\mathbf{1 0}) \\
\text { Mean } \pm \text { SD }\end{array}$ & $\begin{array}{l}\text { Group III } \\
(\mathbf{n}=\mathbf{1 0}) \\
\text { Mean } \pm \text { SD }\end{array}$ \\
\hline PI & $\begin{array}{l}\text { At base-line } \\
1 \text { month } \\
3 \text { months } \\
6 \text { months } \\
12 \text { months }\end{array}$ & $\begin{array}{l}1.07 \pm 0.62 \\
0.72 \pm 0.25 \\
0.40 \pm 0.29^{*} \\
0.35 \pm 0.24^{*} \\
0.35 \pm 0.24^{*}\end{array}$ & $\begin{array}{l}1.35 \pm 0.64 \\
0.65 \pm 0.21^{*} \\
0.47 \pm 0.14^{*} \\
0.45 \pm 0.10^{*} \\
0.42 \pm 0.12^{*}\end{array}$ & $\begin{array}{l}1.45 \pm 0.73 \\
0.65 \pm 0.17 * \\
0.50 \pm 0.12^{*} \\
0.47 \pm 0.08^{*} \\
0.47 \pm 0.08^{*}\end{array}$ \\
\hline GI & $\begin{array}{l}\text { At base-line } \\
1 \text { month } \\
3 \text { months } \\
6 \text { months } \\
12 \text { months }\end{array}$ & $\begin{array}{l}1.30 \pm 0.35 \\
1.05 \pm 0.37 \\
0.45 \pm 0.37 * \\
0.30 \pm 0.26^{*} \\
0.20 \pm 0.26^{*}\end{array}$ & $\begin{array}{l}1.35 \pm 0.70 \\
0.82 \pm 0.17 * \\
0.52 \pm 0.18^{*} \\
0.37 \pm 0.13^{*} \\
0.35 \pm 0.12 *\end{array}$ & $\begin{array}{l}1.35 \pm 0.66 \\
0.80 \pm 0.23 * \\
0.52 \pm 0.18 * \\
0.40 \pm 0.17 * \\
0.30 \pm 0.23 *\end{array}$ \\
\hline PPD & $\begin{array}{l}\text { At base line } \\
6 \text { months } \\
12 \text { months }\end{array}$ & $\begin{array}{l}1.40 \pm 0.58 \\
1.33 \pm 0.30 \\
1.28 \pm 0.27\end{array}$ & $\begin{array}{l}1.55 \pm 0.45 \\
1.48 \pm 0.24 \\
1.37 \pm 0.28\end{array}$ & $\begin{array}{l}1.43 \pm 0.44 \\
1.23 \pm 0.22 \\
1.20 \pm 0.22\end{array}$ \\
\hline CAL & $\begin{array}{l}\text { At base line } \\
6 \text { months } \\
12 \text { months }\end{array}$ & $\begin{array}{l}2.83 \pm 0.94 \\
1.78 \pm 0.48^{*} \\
1.55 \pm 0.25^{*}\end{array}$ & $\begin{array}{l}2.87 \pm 0.41 \\
1.68 \pm 0.29 * \\
1.60 \pm 0.20 *\end{array}$ & $\begin{array}{l}2.33 \pm 0.54 \\
1.53 \pm 0.51 \\
1.50 \pm 0.44\end{array}$ \\
\hline RH & $\begin{array}{l}\text { At base line } \\
1 \text { month } \\
3 \text { months } \\
6 \text { months } \\
12 \text { months }\end{array}$ & $\begin{array}{l}2.45 \pm 1.21 \\
1.10 \pm 0.84 * \\
0.45 \pm 0.50 * \\
0.40 \pm 0.51 * \\
0.40 \pm 0.51 *\end{array}$ & $\begin{array}{l}2.00 \pm 0.82 \\
0.45 \pm 0.68 * \\
0.45 \pm 0.68 * \\
0.45 \pm 0.68 * \\
0.45 \pm 0.68 *\end{array}$ & $\begin{array}{l}1.75 \pm 0.63 \\
0.25 \pm 0.35^{*} \\
0.25 \pm 0.35^{*} \\
0.30 \pm 0.25 * \\
0.30 \pm 0.25 *\end{array}$ \\
\hline
\end{tabular}

* Significant change over time within group compared with baseline value. $(* \mathrm{P}<0.05)$

†, Significant difference between the three groups at different follow-up periods $(\dagger \mathrm{P}<0.05)$

Group I = Patients treated with connective tissue graft + coronally advanced flap

Group II = Patients treated with chitosan membrane + coronally advanced flap

Group III =Patients treated with chitosan membrane + autologous platelet-rich plasma + coronally advanced flap 
Table (2): Mean values of plaque index (PI), gingival index (GI), probing pocket depth (PPD in mm), clinical attachment level (CAL in mm), recession height (RH in mm) among the study groups at evaluation periods.

\begin{tabular}{|c|c|c|c|c|}
\hline Variable & Group & $\begin{array}{l}\text { Group I } \\
(\mathbf{n}=\mathbf{1 0}) \\
\text { Mean } \pm \text { SD }\end{array}$ & $\begin{array}{l}\text { Group II } \\
(\mathbf{n}=\mathbf{1 0}) \\
\text { Mean } \pm \text { SD }\end{array}$ & $\begin{array}{l}\text { Group III } \\
(\mathbf{n}=\mathbf{1 0}) \\
\text { Mean } \pm \text { SD }\end{array}$ \\
\hline RW & $\begin{array}{l}\text { At base-line } \\
1 \text { month } \\
3 \text { months } \\
6 \text { months } \\
12 \text { months }\end{array}$ & $\begin{array}{l}4.20 \pm 0.42 \\
1.75 \pm 1.27^{*} \\
1.00 \pm 1.25^{*} \\
0.80 \pm 1.13^{*} \\
0.80 \pm 1.13^{*}\end{array}$ & $\begin{array}{l}4.00 \pm 0.64 \\
0.80 \pm 1.13^{*} \\
0.70 \pm 1.05^{*} \\
0.70 \pm 1.05^{*} \\
0.70 \pm 1.05^{*}\end{array}$ & $\begin{array}{l}4.40 \pm 0.52 \\
0.50 \pm 0.96^{* \dagger} \\
0.60 \pm 0.96^{*} \\
0.50 \pm 0.52 * \\
0.50 \pm 0.52 *\end{array}$ \\
\hline HKT & $\begin{array}{l}\text { At base-line } \\
1 \text { month } \\
3 \text { months } \\
6 \text { months } \\
12 \text { months }\end{array}$ & $\begin{array}{l}4.00 \pm 2.00 \\
5.40 \pm 1.78 \\
6.40 \pm 1.78 \\
6.70 \pm 1.64^{*} \\
6.70 \pm 1.64^{*}\end{array}$ & $\begin{array}{l}4.90 \pm 0.99 \\
6.00 \pm 1.05 \\
6.10 \pm 0.87^{*} \\
6.10 \pm 0.87^{*} \\
6.10 \pm 0.87^{*}\end{array}$ & $\begin{array}{l}5.20 \pm 1.75 \\
6.90 \pm 1.85 \\
6.90 \pm 1.59 \\
6.90 \pm 1.59 \\
7.00 \pm 0.95 *\end{array}$ \\
\hline $\mathrm{RC}$ & $\begin{array}{l}1 \text { month } \\
3 \text { months } \\
6 \text { months } \\
12 \text { months }\end{array}$ & $\begin{array}{l}74.10 \% \pm 0.21 \\
82.80 \% \pm 0.15 \\
87.80 \% \pm 0.16 \\
87.80 \% \pm 0.16\end{array}$ & $\begin{array}{l}87.30 \% \pm 0.17 \\
87.30 \% \pm 0.17 \\
87.30 \% \pm 0.17 \\
87.30 \% \pm 0.17\end{array}$ & $\begin{array}{l}91.67 \% \pm 0.14 \\
91.67 \% \pm 0.14 \\
89.33 \% \pm 0.13 \\
89.33 \% \pm 0.13\end{array}$ \\
\hline WHI & $\begin{array}{l}14 \text { days } \\
1 \text { month } \\
3 \text { months } \\
6 \text { months }\end{array}$ & $\begin{array}{l}1.55 \pm 0.53 \\
1.00 \pm 0.00 * \\
1.00 \pm 0.00 * \\
1.00 \pm 0.00 *\end{array}$ & $\begin{array}{l}1.00 \pm 0.00^{\dagger} \\
1.00 \pm 0.00 \\
1.00 \pm 0.00 \\
1.00 \pm 0.00\end{array}$ & $\begin{array}{l}1.00 \pm 0.00^{\dagger} \\
1.00 \pm 0.00 \\
1.00 \pm 0.00 \\
1.00 \pm 0.00\end{array}$ \\
\hline GT & $\begin{array}{l}\text { Base-line } \\
12 \text { months }\end{array}$ & $\begin{array}{l}1.00 \pm 0.00 \\
1.35 \pm 0.24 *\end{array}$ & $\begin{array}{l}1.00 \pm 0.00 \\
1.20 \pm 0.26^{*}\end{array}$ & $\begin{array}{l}1.00 \pm 0.00 \\
1.35 \pm 0.34 *\end{array}$ \\
\hline $\begin{array}{l}\text { area of } \\
\text { recession }\end{array}$ & $\begin{array}{l}\text { At base line } \\
1 \text { month } \\
3 \text { months } \\
6 \text { months } \\
12 \text { months }\end{array}$ & $\begin{array}{l}8.71 \pm 2.64 \\
3.10 \pm 3.17 * \\
1.61 \pm 2.02 * \\
1.67 \pm 1.53 * \\
1.58 \pm 1.52 *\end{array}$ & $\begin{array}{l}7.02 \pm 2.89 \\
1.74 \pm 2.65 * \\
1.66 \pm 2.70 * \\
1.54 \pm 2.66 * \\
1.49 \pm 2.53 *\end{array}$ & $\begin{array}{l}6.50 \pm 1.92 \\
0.76 \pm 0.68 * \dagger \\
0.85 \pm 0.50 * \\
0.88 \pm 0.64 * \\
0.81 \pm 0.59 *\end{array}$ \\
\hline
\end{tabular}

Significant change over time within group compared with baseline value. $(* \mathrm{P}<0.05)$

${ }^{\dagger}$ Significant difference between the three groups at different follow-up periods $(\dagger \mathrm{P}<0.05)$

Group I = Patients treated with connective tissue graft + coronally advanced flap

Group II = Patients treated with chitosan membrane + coronally advanced flap

Group III =Patients treated with chitosan membrane + autologous platelet-rich plasma + coronally advanced flap 


\section{References}

1- Trombelli L. Periodontal regeneration in gingival recession defects. Periodontol.1999, 19, 138-150.

2- Cueva MA, Boltchi FE and Hallmon WW. A comparative study of coronally advanced flaps with and without the addition of enamel matrix derivative in the treatment of marginal tissue recession. J Periodontol. 2004, 75, 949-956.

3- Kassab MM and Cohen RE. Treatment of gingival recession. $J$ Am Dent Assoc. 2002,133, 1499-1506.

4- Allen EP and Miller PD. Coronal positioning of existing gingiva: short term results in the treatment of shallow marginal tissue recession. J Periodontol.1989, 60, 316-319.

5- Harris RJ and Harris AW. The coronally positioned pedicle graft with inlaid margins: A predictable method to obtain root coverage of shallow defects. Int J Periodontics Restorative Dent. 1994, 14, 229-241.

6- Trombelli L, Scabbia A and Wikesjö UM. Fibrin glue application in conjunction with tetracycline root conditioning and coronally positioned flap procedure in the treatment of human gingival recession defects. J ClinPeriodontol.1996, 23, 861-867.

7- Pini Prato GP, Baldi C and Pagliaro G.Coronally advanced flap procedure for root coverage. Treatment of root surface: Root planing versus polishing. J Periodontol.1999, 70, 1064-1076.

8- Berlucchi I, Francetti L and Del Fabbro M. The influence of anatomical features on the outcome of gingival recessions treated with coronally advanced flap and enamel matrix derivative: a 1-year prospective study. J Periodontol. 2005, 76, 899-907.

9- Wilson TG Jr, McGuire MK and Nunn ME. Evaluation of the safety and efficacy of periodontal applications of a living tissueengineered human fibroblast-derived dermal substitute. II. Comparison to the subepithelial connective tissue graft: a randomized controlled feasibility study. J Periodontol.2005, 76, 881-889.

10- Cetiner D, Bodur A and Uraz A. Expanded mesh connective tissue graft for the treatment of multiple gingival recessions. $J$ Periodontol.2004, 75, 1167-72.

11- Clauser C, Nieri $M$ and Franceschi D. Evidence-based mucogingival therapy. Part 2: Ordinary and individual patient data meta-analyses of surgical treatment of recession using complete root coverage as the outcome variable. $J$ Periodontol.2003, 74,741-756.

12- Alkan A, Keskiner I and Yuzbasioglu E. Connective tissue grafting on resin ionomer in localized gingival recession. $J$ Periodontol.2006, 77, 1446-14451.

13- Nyman S, Gottlow J and Lindhe J. New attachment formation by guided tissue regeneration. J Periodontal Res.1987, 22, 252254.

14- Tal H, Pitaru S and Moses O. Collagen gel and membrane in guided tissue regeneration in periodontal fenestration defects in dogs. J ClinPeriodontol.1996, 23,1-6.

15- Garrett S, Loos B and Chamberlain D. Treatment of intraosseous periodontal defects with a combined adjunctive therapy of citric acid conditioning, bone grafting, and placement of collagenous membranes. J ClinPeriodontol.1988, 15, 383389.

16- Warrer K, Karring T and Nyman S. Guided tissue regeneration using biodegradable membranes of polylactic acid or polyurethane. J ClinPeriodontol.1992, 19, 633-640.

17- Ziccardi VB and Buchbinder D. Guided tissue regeneration in dentistry. N Y State Dent J.1996, 62, 48-51.

18- Marx RE, Carlson ER and Eichstaedt RM. Platelet-rich plasma: growth factor enhancement for bone grafts. Oral Surg Oral Med Oral Pathol Oral RadiolEndod. 1998, 85, 638-46.

19- Sanchez AR, Sheridan PJ and Kupp LI. Is platelet-rich plasma the perfect enhancement factor? A current review. Int J Oral Maxillofac Implants.2003, 18, 93-103.

20- Clark AM. Natural products as a resource for new drugs. Pharm Res.1996, 13, 1133-44.

21- Cao CF and Sun XP. Herbal medicine for periodontal diseases. Int Dent J.1998, 43, 316-22.
22- Pang EK, Paik JW and Kim SK. Effects of chitosan on human periodontal ligament fibroblasts in vitro and on bone formation in rat calvarial defects. $J$ Periodontol. 2005, 76, 1526-33.

23- Muzzarelli R, Baldassarre V and Conti F. Biological activity of chitosan: ultrastructural study. Biomaterials. 1988, 9, 247-52.

24- Muzzarelli R, Tarsi R and Filippini O. Antimicrobial properties of N-carboxybutyl chitosan. Antimicrob Agents Chemother.1990, 34, 2019-23.

25- Roller S and Covill N. The antifungal properties of chitosan in laboratory media and apple juice. Int J Food Microbiol.1999, 1, 67-77.

26- Aksungur P, Sungur A and Unal S. Chitosan delivery systems for the treatment of oral mucositis: in vitro and in vivo studies. $J$ Control Release. 2004, 11, 269-79.

27- Sillness P, Loe J. Periodontal diseases (II): Correlation between oral hygiene and periodontal conditions. ActaOdonto Scand. 1964, 22, 121-126.

28- Loe JB and Silness P. Periodontal diseases in pregnancy (I): Prevalence and severity. Acta. Odonto. Scand.21:1963, 522

29- Ramfjord SP. The periodontal index. J Periodontol. 1967, 38, 602-8.

30- Huang LH, Neiva RE and Soehren SE. The effect of plateletrich plasma on the coronally advanced flap root coverage procedure: a pilot human trial. J Periodontol.2005, 76, 1768-77.

31- Langer B and Langer L.Subepithelial connective tissue graft technique for root coverage. J Periodontol.56:1985, 715-20.

32- Jenkins S, Addy M and Wade W. the mechanism of action of chlorhexidine. J ClinPeriodontol. 1988, 15, 415-424.

33- Choi BK, Kim KY and Yoo YJ. In vitro antimicrobial activity of a chitooligosaccharide mixture against Actinobacillusactinomycetemcomitans and Streptococcus mutans. Int $J$ Antimicrob Agents.2001, 18, 553-557.

34- Chou TC, Fu E and Shen EC. Chitosan inhibits prostaglandin E2 formation and cyclooxygenase-2 induction in lipopolysaccharide-treated RAW 264.7 macrophages. BiochemBiophys Res Commun.2003, 308, 403-403.

35- Jenkiins JK, Malyak M and Arcnd WP. The effects of interleukin 10 on interleukin-1 receptor and antagonist and interleukin-1 production in human monocytes and neurtrophils, Lymphokine. Cytokine Res. 1994, 13, 47-54.

36- Barry OP, Praticò D and Savani RC. Modulation of monocyteendothelial cell interactions by platelet microparticles. J Clin Invest.1998, 102,136-44.

37- Appay V, Brown A and Cribbes S. Aggregation of RANTES is responsible for its inflammatory properties. Characterization of nonaggregating, noninflammatory RANTES mutants. $J$ Biol Chem. 1999, 274, 27505-12

38- El-Sharkawy H, Kantarci A and Deady J. Platelet-rich plasma: growth factors and pro- and anti-inflammatory properties. $J$ Periodontol.2007, 78, 661-9.

39- de Obarrio JJ, Araúz-Dutari JI and Chamberlain TM. The use of autologous growth factors in periodontal surgical therapy: platelet gel biotechnology--case reports. Int J Periodontics Restorative Dent.2000, 20, 486-97.

40- Rollins BJ, Walz A and Baggiolini M. Recombinant human $\mathrm{MCP}-1 / \mathrm{JE}$ induces chemotaxis, calcium flux, and the respiratory burst in human monocytes. Blood. 1991, 78, 1112-6.

41- Muzzarelli R, Biagini G and Pugnaloni A. Reconstruction of parodontal tissue with chitosan. Biomaterials10: 1989, 598-603.

42- Akncibay H, Senel S and Ay ZY. Application of chitosan gel in the treatment of chronic periodontitis. J Biomed Mater Res B ApplBiomater. 2007, 80, 290-296.

43- Zhang Y, Wang Y and Shi B. A platelet-derived growth factor releasing chitosan/coral composite scaffold for periodontal tissue engineering. Biomaterials. 2007, 28, 1515-1522.

44- Camargo PM, Lekovic V, Camargo PM and Weinlaender M. Comparison of platelet-rich plasma, bovine porous bone mineral, and guided tissue regeneration versus platelet-rich plasma and bovine porous bone mineral in the treatment of intrabony defects: a reentry study. J Periodontol. 2002, 73, 198205 . 
45- Lekovic V, Camargo PM and Weinlaender M. Comparison of platelet-rich plasma, bovine porous bone mineral, and guided tissue regeneration versus platelet-rich plasma and bovine porous bone mineral in the treatment of intrabony defects: a reentry study. J Periodontol. 2002, 73, 198-205.

46- Okuda K, Kawase T and Momose M. Platelet-rich plasma contains high levels of platelet-derived growth factor and transforming growth factor-beta and modulates the proliferation of periodontally related cells in vitro. J Periodontol.2003, 74, 849-57.

47- Bosch C, Melsen B and Gibbons R. Human recombinant transforming growth factor-beta 1 in healing of calvarial bone defects. J Craniofac Surg.1996, 7, 300-10.

48- Papageorgakopoulos G, Greenwell H and Hill M. Root coverage using acellular dermal matrix and comparing a coronally positioned tunnel to a coronally positioned flap approach. $J$ Periodontol. 2008, 79, 1022-30.

49- Goldman H, Schluger S and Fox L. Periodontal Therapy, 3rd ed. St. Louis: C.V. Mosby Co.;1964:560

50- Borghetti A and Gardella JP. Thick gingival autograft for the coverage of gingival recession: a clinical evaluation. Int $J$ Periodontics Restorative Dent.1990, 10, 216-29.

51- Harris RJ. Root coverage with connective tissue grafts: an evaluation of short- and long-term results. J Periodontol.2002, 73, 1054-9.

52- Lee EJ, Meraw SJ and Oh TJ. Comparative histologic analysis of coronally advanced flap with and without collagen membrane for root coverage. J Periodontol.2002, 73, 779-88.

53- Cetiner D, Parlar A, Baloş K, Alpar R. Comparative clinical study of connective tissue graft and two types of bioabsorbable barriers in the treatment of localized gingival recessions. $J$ Periodontol. 2003, 74, 1196-205.

54- Ainamo J and Talari A. The increase with age of the width of attached gingival. J Periodontal Res.1976, 11, 182-188.

55- Pini Prato G, Clauser C, Cortellini P,. Guided tissue regeneration versus mucogingival surgery in the treatment of human buccal recessions. A 4-year follow up study. $J$ Periodontol.1996, 67, 1216-1223.

56- Wennström JL and Zucchelli G. Increased gingival dimensions. A significant factor for successful outcome of root coverage procedures? A 2-year prospective clinical study. $J$ ClinPeriodontol. 1996, 23, 770-7.

57- Wang HL, Bunyaratavej P, Labadie M, et al. Comparison of 2 clinical techniques for treatment of gingival recession. $J$ Periodontol. 2001, 72, 1301-11.

58- McGuire MK and Nunn M. Evaluation of human recession defects treated with coronally advanced flaps and either enamel matrix derivative or connective tissue. Part 1: Comparison of clinical parameters. J Periodontol.2003, 74, 1110-25.

59- Hwang D and Wang HL. Flap thickness as a predictor of root coverage: a systematic review. J Periodontol.2006, 77, 1625-34.

60- Muller HP, Eger T and Schorb A. Gingival dimensions after root coverage with free connective tissue grafts. $J$ ClinPeriodontol.1998, 25(5), 424-30.

61- Mattioli-Belmonte M, Muzzarelli B, and Muzzarelli RAA. Chitin and chitosan in wound healing and other biomedical applications. Carbohydr Europe 1997, 19, 30-36.

62- Howling GI, Dettmar PW, Goddard PA et al. The effect of chitin and chitosan on the proliferation of human skin fibroblasts and keratinocytes in vitro. Biomaterials. 2001, 22, 2959-2966.

63- Inui H, Tsujikubo M. and Hirano S. Low molecular weight chitosan stimulation of mitogenic response to platelel-derived growth factor in vascular smooth muscle cells. Biosci Biotech Biochem. 1995, 59, 2111-4.

64- Matsuda N, Lin WL and Kumar NM .Mitogenic, chemotactic, and synthetic responses of rat periodontal ligament fibroblastic cells to polypeptide growth factors in vitro. J Periodontol. 1992, 63, 515-25.

65- Bartold PM. Platelet-derived growth factor stimulates hyaluronate but not proteoglycan synthesis by human gingival fibroblasts in vitro. J Dent Res. 1993, 72, 1473-80.
Author's Biography:

Enas Ahmed Elgendy

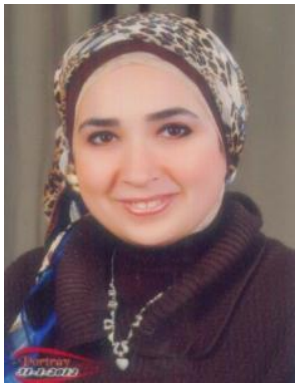

Lecturer in oral Medicine, Periodontology, Diagnosis and oral Radiology department, Faculty of dentistry October 6 University.

E-mail: $\quad$ enaselgendy2005@yahoo.co.uk

Samia Ahmed Darwish and Samia Nabawy Serag Prof. of Oral Medicine, Periodontology, Oral Diagnosisand Radiology Department, Faculty of Dentistry, Tanta University Amal Mohamed Aldeeb

Prof. of Oral Pathology Department, Faculty of Dentistry, Tanta University 